From global bioethics to ethical governance of biomedical research collaborations

Wahlberg, Ayo; Rehmann-Sutter, Christoph; Sleeboom-Faulkner, Margaret; Lu, Guangxiu; Döring, Ole; Cong, Yali; Laska-Formejster, Alicja; He, Jing; Chen, Haidan; Gottweis, Herbert; Rose, Nikolas

Published in:

Social Science \& Medicine

DOI:

10.1016/j.socscimed.2013.03.041

Publication date:

2013

Document version

Early version, also known as pre-print

Citation for published version (APA):

Wahlberg, A., Rehmann-Sutter, C., Sleeboom-Faulkner, M., Lu, G., Döring, O., Cong, Y., Laska-Formejster, A., He, J., Chen, H., Gottweis, H., \& Rose, N. (2013). From global bioethics to ethical governance of biomedical research collaborations. Social Science \& Medicine, 98, 293-300.

https://doi.org/10.1016/j.socscimed.2013.03.041 
This paper has been accepted for publication in Social Science \& Medicine, and the final (edited, revised and typeset) version of this paper will be published in Social Science \& Medicine, Volume 98, by Elsevier, All rights reserved. (C) Elsevier

\section{From global bioethics to ethical governance of biomedical research collaborations}

\section{Author list}

- Ayo Wahlberg, Department of Anthropology, University of Copenhagen, Denmark

- Christoph Rehmann-Sutter, Department of Medical History and Science Studies, University of Luebeck, Germany

- Margaret Sleeboom-Faulkner, Department of Anthropology, University of Sussex, United Kingdom

- Lu Guangxiu, Reproductive and Genetic Hospital, CITIC-Xiangya, Changsha, P.R. China

- Ole Doering, German Institute of Global and Area Studies, Hamburg, Germany

- Cong Yali, Centre for Medical Ethics, Peking Unviersity Health Science Centre, Beijing, P.R. China

- Nikolas Rose, Department of Social Science, Health and Medicine, King's College London, United Kingdom

- He Jing, Reproductive and Genetic Hospital, CITIC-Xiangya, Changsha, China

- Chen Haidan, Center for STS, Zhejiang University, P.R. China

- Herbert Gottweis, Department of Political Science, University of Vienna, Austria

- Alicja Laska-Formejster, Department of Sociology, Univesrity of Lodz, Poland

\section{Corresponding author}

Ayo Wahlberg, ayo.wahlberg@anthro.ku.dk

\section{Acknowledgments}

We would like to acknowledge the financial support of the European Commission's Sixth Framework Programme (FP6), the UK Medical Research Council and the Wellcome Trust. We would also like to thank all BIONET partners, BIONET exchange students and participants in our workshops and conferences for their engagement with BIONET and the frank and open dialogue that formed the basis of our findings.

\section{Keywords}

Global bioethics, ethical governance, regulation, research collaboration, informed consent, People's Republic of China, Europe 
This paper has been accepted for publication in Social Science \& Medicine, and the final (edited, revised and typeset) version of this paper will be published in Social Science \& Medicine, Volume 98, by Elsevier, All rights reserved. (C) Elsevier

\begin{abstract}
One of the features of advanced life sciences research in recent years has been its internationalisation, with countries such as China and South Korea considered 'emerging biotech' locations. As a result, crosscontinental collaborations are becoming common generating moves towards ethical and legal standardisation under the rubric of 'global bioethics'. Such a 'global', 'Western' or 'universal' bioethics has in turn been critiqued as an imposition upon resource-poor, non-Western or local medical settings. In this article, we propose that a different tack is necessary if we are to come to grips with the ethical challenges that inter-continental biomedical research collaborations generate. In particular we ask how national systems of ethical governance of life science research might cope with increasingly global research collaborations with a focus on Sino-European collaboration. We propose four 'spheres' deliberation, regulation, oversight and interaction - as a helpful way to conceptualise national systems of ethical governance. Using a workshop-based mapping methodology we identified three specific ethical challenges arising from cross-continental research collaborations: 1) ambiguity as to which regulations are applicable; 2) lack of ethical review capacity not only among ethical review board members but also collaborating scientists; 3 ) already complex, researcher-research subject interaction is further complicated when many nationalities are involved.
\end{abstract}

\title{
Introduction
}

In November 2008, a few hundred pharmaceutical industry representatives from China, Europe and other parts of the world met in Shanghai for China Trials 2008 an event billed by its organisers as "Your gateway to conducting clinical trials in China... If you're an emerging biotech or pharma company interested in conducting trials in China, you will learn exactly how much time and money you can save, how acceptable your China data is for submission to the FDA/EMEA" (China Trials 2008). A few months later, in February 2009, the Sino-Danish Breast Cancer Research Centre was inaugurated bringing together Danish and Chinese geneticists with an aim "to solve some of the most urgent problems in modern treatment of breast cancer" (BCRC 2012).

What kinds of ethical challenges does such an ongoing globalisation of biomedical research collaborations give rise to 'on the ground' in all those spaces and processes 
This paper has been accepted for publication in Social Science \& Medicine, and the final (edited, revised and typeset) version of this paper will be published in Social Science \& Medicine, Volume 98, by Elsevier, All rights reserved. (C) Elsevier

where bench and bedside intersect and overlap? From a biomedical point of view research depends, on the one hand, on volunteer human subjects - either as donors of human biological materials (e.g. gametes, embryos, blood, bone marrow, tissue) and/or biographical information (e.g. medical history, lifestyle details, socio-economic background), or as participants in clinical research (e.g. in randomised controlled trials or as recipients of experimental therapies) - and on the other, scientists, medical professionals as well as other research support staff who operate within particular regulatory, socio-economic, technological, institutional and cultural settings. At the same time, standardized technological developments have made it possible to globalise research as biological samples procured in one place, can be biologically cultured and/or biochemically/genetically analysed in another, and the information derived can be digitalised and electronically transported throughout the world together with associated biographical information. This also means that biomedical treatments developed in one place can be transferred to another country or region for clinical testing.

In this article, we ask how national systems of ethical governance of these kinds of biological and biomedical research might cope with increasingly global life science research collaborations with a specific focus on Sino-European biomedical research collaboration. Ethical governance is not just about how guidelines and regulations are implemented and followed. Rather, it involves a complex system whereby research practice is guided not only by requirements of scientific rigour but equally importantly by respect for the rule of law, transparency, scientific and ethical accountability and freedom from corruption. Our guiding research question has been: what happens when biomedical 
This paper has been accepted for publication in Social Science \& Medicine, and the final (edited, revised and typeset) version of this paper will be published in Social Science \& Medicine, Volume 98 , by Elsevier, All rights reserved. (C) Elsevier

research collaboration is initiated across continents involving multiple legal systems, administrative requirements, ethical review procedures, socio-economic conditions and cultural contexts? It is the ethical challenges that emerge specifically as a result of the exchange of researchers, biomedical treatments, scientific equipment, biological materials, sequencing data and/or information databases across continents and countries that will be analysed and discussed in the following.

One response to the ongoing globalisation of biomedical research has been a concerted effort to achieve some kind of global consensus around core bioethical principles led by, for example, UNESCO, WHO and the Council for International Organizations of Medical Sciences (CIOMS). Through a series of guidelines and declarations, these organisations have called for a 'global bioethics': "a universal framework of principles and procedures to guide States in the formulation of their legislation, policies or other instruments in the field of bioethics" (UNESCO 2005). At the same time, nation states are of course engaged in building up their own national infrastructures of ethical governance of biomedical research. We therefore argue that a change of tack is necessary - from focussing on global bioethics to the ethical governance of global biomedical research collaborations - if we are to understand the challenges that arise 'on the ground' when nationally-anchored procedures of ethical governance intersect in contexts of global collaboration.

We begin this article by highlighting three important sets of critiques of global bioethics as a way to contextualise our own approach to examining national infrastructures of 
This paper has been accepted for publication in Social Science \& Medicine, and the final (edited, revised and typeset) version of this paper will be published in Social Science \& Medicine, Volume 98, by Elsevier, All rights reserved. (C) Elsevier

ethical governance. We then set out our workshop-based methodology, which was designed as a mapping exercise to document already existing or emerging ethical governance practices, structures and challenges in China and Europe, within the specific fields of regenerative medicine, genomic and clinical research over three years (November 2006 to September 2009). In the main section of the article, we present our explorative findings through our discussion of the ways in which distinct national systems of ethical governance are challenged by global biomedical research collaborations. We have found it empirically helpful to distinguish between four important 'layers' or 'spheres' that make up systems of ethical governance of biological and biomedical research. Firstly, many countries (not least in Europe and China) have developed organised processes of national ethical deliberation in order to debate science directions as a matter of stewardship. Secondly, these same countries have also, especially since the latter half of the $20^{\text {th }}$ century, formulated and passed various types of ethical regulation whether in the form of laws, guidelines or standards. Thirdly, these various forms of ethical regulation often stipulate mandatory ethical oversight of biomedical research involving volunteer human subjects with the ethics review committee or institutional review board as the dominant organisational form. And finally, ethical interaction consists of all those moments when scientists/clinicians and research subjects/patients come into contact with each other, whether in contexts of recruitment, participation or follow-up in a biomedical research project.

Each layer or sphere, and the various ways in which they overlap and interact, forms a part of national ethical governance infrastructures. And while each sphere merits specific 
This paper has been accepted for publication in Social Science \& Medicine, and the final (edited, revised and typeset) version of this paper will be published in Social Science \& Medicine, Volume 98, by Elsevier, All rights reserved. (C) Elsevier

attention in and of themselves in any country, in this paper we identify the specific challenges that arise in each of these spheres when national systems of ethical governance intersect in the context of cross-continental research collaboration.

\section{Global biomedicine, global bioethics}

Over the last two decades, a number of scholars have critically examined the unfolding globalisation of biomedical research, while also pointing to colonial legacies of medical ‘field’ research (see Angell 1997; Varmus \& Satcher 1997; Mbidde 1998; Sunder Rajan 2006; Bharadwaj 2009; Gottweis 2009; Sleeboom-Faulkner 2009 \& 2010; Petryna 2009; Ong 2010; Crane 2010; Geissler \& Molyneux 2011). What they have shown is that alongside the globalisation of biomedical research in recent years, we have also seen "growing moves towards ethical, legal and regulatory standardisation around the globe" (Bharadwaj 2009: 96) as "the dispersal of genetic science across the world raises questions about the interactions of biotechnologies and bioethics in diverse global locations" (Ong 2010: 1). Critical studies of formalistic bioethics - as found in declarations, principles, guidelines and regulations - have long highlighted problems that can arise when a universalised set of principles travels out into a 'messy' field only to be 'operationalised' in diverse historical, cultural and socio-economic contexts (see Crane 2010). We might broadly distinguish between three forms of critique which are related to 1) resource-poor settings, 2) culture and value dimensions and 3) so-called 'situational ethics'. 
This paper has been accepted for publication in Social Science \& Medicine, and the final (edited, revised and typeset) version of this paper will be published in Social Science \& Medicine, Volume 98, by Elsevier, All rights reserved. (C) Elsevier

The first of these sets of critique focuses on the problem of harmonizing ethical review practices "in the 'overseas' situation of unequal scientific and technical capacity and great disparities in power and wealth" (Geissler \& Molyneux 2011: 2; see also Bhutta 2004; Crane 2010; Resnik 1998, DeCosta et al. 2004, Molyneux et al. 2005, Geisler et al. 2008). Such critiques point to the material, technical, regulatory and capacity-related challenges of ensuring ethical oversight and protection when research is carried out in socalled 'resource-poor' settings which are seen as particularly vulnerable.

A second set of critiques has focused on the 'Eurocentric' basis of bioethical principles as espoused in such documents as the Helsinki Declaration or the Universal Declaration on Bioethics and Human Rights: "Western moral analyses, processes, and solutions are not transportable to all bioethical contexts around the world... [rather they] must be recast radically to take account of the particular moral context that defines the complex character of [east Asian] culture" (Alora \& Lumitao 2001: 4; see also Qiu 2004; Tangwa 1996). This line of cultural critique, which has especially (but not only) developed in Asia, speaks against a perceived 'ethical imperialism' and calls for cross-cultural dialogues based on mutual understanding and respect.

Finally, a third set of critiques has emerged out of ethnographic engagement with those communities within which biomedical research is taking place. In these critiques, "anthropologists have variously posed relational and situational ethics as counters to the claims of universal systemic ethics" (Ong 2011: 12; see also Petryna 2007; Bharadwaj 2009; Sleeboom-Faulkner 2010; Molyneux \& Geissler 2008), since ethics are seen as 
This paper has been accepted for publication in Social Science \& Medicine, and the final (edited, revised and typeset) version of this paper will be published in Social Science \& Medicine, Volume 98, by Elsevier, All rights reserved. (C) Elsevier

emerging in response to particular practices rather than as something that can be imposed from without. Ethnographic studies of 'research subject communities' show how there is considerable 'ethical variability' or 'ethical flexibility' depending on the context within which research is being carried out, most visibly perhaps in contexts of public health crisis, raising questions about the feasibility of a universalised bioethics.

Each of these three forms of critique is premised on the imposition of an ethical framework ('Western' or 'universal') considered external, detached or alien to a given situation. In this article we shift focus to the specific ethical challenges that intercontinental biomedical research collaborations generate. That is to ask, what happens when scientists from two different continents join forces to engage in cross-border collaborative research? For if it is the case that individual countries are actively building up national structures and procedures for the ethical governance of biological and biomedical research then it is necessary to consider how such national systems of ethical governance might cope with increasingly global life science research collaborations.

\section{Methodology - mapping ethical governance practices}

The data for this article has been generated through a large-scale Sino-European collaboration over a three-year period (2006-2009) called BIONET. A total of five explorative workshops and conferences were held in cities throughout China (Beijing, Shanghai, Changsha, Xian and Shenzhen) focusing on the fields of 1) reproductive and regenerative medicine; 2) clinical trials; and 3) biobanking and genomic research. A final conference was organised in London to identify and reflect on key findings and to 
This paper has been accepted for publication in Social Science \& Medicine, and the final (edited, revised and typeset) version of this paper will be published in Social Science \& Medicine, Volume 98, by Elsevier, All rights reserved. (C) Elsevier

identify avenues for future collaboration. The objective of these events was to map out ethical governance practices in China and Europe within these fields of biomedical research as a way to inform, prepare, inspire and facilitate cross-cultural exchange on matters of common concern as well as to begin thinking about what ethical governance of international research collaborations might look like.

The workshops and conferences were each approximately five days in length and included fifty to sixty participants with a core group of people who attended all of them which provided overlap. Systematic mapping research was carried out by BIONET partners and by a group of post graduate students who had competitively applied for BIONET research grants.

All in all the events were attended by approximately 300 clinicians, life scientists, lawyers, ethicists, government officials, policymakers, social scientists and others from China and Europe with specific expertise and experience in the fields of research that were being explored. Participants were not representative of either China or Europe, but were actively engaged with issues around the ethical governance of biomedical research in both regions. Workshops and conferences consisted of presentations on the current state of ethical governance of advanced biomedical research in both China and Europe with ample time for discussion and debate between European and Chinese participants. Speakers were asked to identify key ethical challenges arising from stem cell, clinical and genomics research from their respective disciplinary perspectives. Presentations and discussions were recorded and reports were prepared from each event summarising key 
This paper has been accepted for publication in Social Science \& Medicine, and the final (edited, revised and typeset) version of this paper will be published in Social Science \& Medicine, Volume 98, by Elsevier, All rights reserved. (C) Elsevier

discussions and presentations. Simultaneous translation was provided at all events to facilitate dialogue (for a complete description of our methodology see BIONET 2010a). The project was carried out in accordance with the ethical requirements of the European Commission.

Our findings, as presented in the following, are not mere summaries of the discussions at our workshops. Rather, they are the result of a synthesis and organisation of the main challenges and themes identified throughout the BIONET project. A BIONET Expert Group consisting of life scientists, ethicists, philosophers and social scientists contributed to the identification of key topics and issues for discussion (BIONET 2010b) and the BIONET group of core scholars met regularly to synthesise and organise the main lessons and findings from each BIONET event.

We have been acutely aware of the limitations of time and outreach, and as a result we make no claims about the ethnographic, representative or definitive value of our findings. Instead we suggest that the presentations, debates and discussions that we have systematically recorded and synthesised in the following allow us to identify important challenges for future attention as cross-cultural biomedical research collaborations increase in scope and number.

\section{Findings and discussion: ethical governance of cross-cultural research collaboration}

Stem cell research, clinical trials and biobanking are very different kinds of biomedical research, each with its particular forms of expertise, infrastructural requirements and 
This paper has been accepted for publication in Social Science \& Medicine, and the final (edited, revised and typeset) version of this paper will be published in Social Science \& Medicine, Volume 98, by Elsevier, All rights reserved. (C) Elsevier

material bases. Yet what they have in common is the challenge of coordination when large-scale research projects are set in motion. From the perspective of researchers, grant applications have to be prepared, laboratories and clinics have to be built and maintained, databases have to be generated and managed, biological samples have to be collected, and volunteers have to be recruited. Moreover, the reliance of advanced biomedical research on human volunteers means that not only is administrative compliance required, so too is ethical adherence as research protocols must be ethically reviewed and approved by ethical review boards and volunteer recruitment processes ethically overseen. This can be challenging enough to coordinate within the confines of a single administrative or bureaucratic system. What then if biomedical research collaboration is initiated across continents involving multiple legal systems, administrative requirements, ethical review procedures, socio-economic conditions and cultural contexts?

As noted earlier, this was a guiding question for us during the course of the discussions and debates that took place at the workshops and conferences held in the period 2006 to 2009. We deliberately chose to focus on ethical governance in the fields of regenerative medicine, clinical trials and biobanking rather than on bioethics as such, as this allowed us to shift analytical attention to the practices that make up such systems of ethical governance, and thereby to explore embedded ethical approaches and unexpected conceptualizations or models of practice. What we found in both China and Europe was that over the last decades, countries have been actively building up infrastructures of ethical governance as a means to organize and ensure the protection of those human subjects who take part in medical research as donors, participants or scientists involved in 
This paper has been accepted for publication in Social Science \& Medicine, and the final (edited, revised and typeset) version of this paper will be published in Social Science \& Medicine, Volume 98, by Elsevier, All rights reserved. (C) Elsevier

challenging innovative research. And, in both regions questions of harmonisation and standardisation have been among the most challenging. Different, however, were the particular configurations within these systems; differences, which could be traced out within what we came to think of as 'spheres' or 'layers' of ethical governance. Each layer or sphere, and the various ways in which they overlap and interact, forms a part of ethical governance systems or regimes. As such, if we are to understand the specific ethical challenges that arise out of trans-national and cross-cultural biomedical research collaborations, then we must have a clear understanding of what each participating scientist/institution 'brings' to a collaboration.

In the following we will introduce each of these spheres - of ethical deliberation, ethical regulation, ethical oversight and ethical interaction - as a way to present some of the differences and challenges we identified during the course of our project. Importantly, these were not only differences between China and Europe, but also often between European countries and between provinces/regions within China.

\section{Organising national deliberation - participatory vs. expert-based governance}

The specific terms under which national ethical governance systems are being built up are often 'set' through some form of ethical deliberation - a kind of national deliberative space in which science directions are debated. Advanced life sciences research has raised a number of specific questions, among scientists and within societies, related to whether or not (and if so in what manner) certain types of biological manipulation of human life should be restricted or prohibited in controlled laboratory settings (e.g. creation of 
This paper has been accepted for publication in Social Science \& Medicine, and the final (edited, revised and typeset) version of this paper will be published in Social Science \& Medicine, Volume 98, by Elsevier, All rights reserved. (C) Elsevier

embryos for research, creation of human-animal cybrids or human cloning). Debates about whether it should be permissible and / or fundable to manipulate and experiment on human zygotes or whether or not enucleated rabbit eggs should be filled with human adult cells have become public affairs, in terms of morality, scientific acceptability and eligibility for funding with public money.

But how do deliberations about direction in scientific research take place in different countries? Is it possible to speak of different forms of stewardship, specific to each national setting (cf. Jasanoff 2007)? In both China and Europe, national ethics commissions and councils have been created to monitor developments in the life sciences as well as to feed into policy processes. Yet, the ways in which a national 'position' has emerged in each country around what forms and manner of life science research should be allowed, restricted or prohibited has been very different. Moreover, national positions can express different views or interests on different levels, such as those of the public, the government, powerful stakeholders, etc., which might not be directly comparable between countries.

If, in Europe, one might speak of a new form of 'participatory governance' in the life sciences arena as "areas of administration and governance that were previously the exclusive domain of technical experts and of meetings behind closed doors are being opened up to public scrutiny and participation" (PAGANINI 2007: 9), then in China we might speak of 'expert governance' where the Ministry of Health and the Ministry of Science and Technology assemble committees with mandates to "carry out researches 
This paper has been accepted for publication in Social Science \& Medicine, and the final (edited, revised and typeset) version of this paper will be published in Social Science \& Medicine, Volume 98, by Elsevier, All rights reserved. (C) Elsevier

and discussions on major ethical issues and put forward their consultative opinions on policies" (MOH 2007: Article 5).

The main differences in forms of stewardship between PRC and Europe (and indeed within these two areas) we identified pertained to the extent to which "inclusion, involvement and mobilisation of extrascientific actors and perspectives are built into a discursive and institutional framework" (Braun \& Kropp 2010: 780). In Europe, it is perhaps especially civil society actors such as religious groups, patient groups and professional organisations that have been particularly vocal in national ethical deliberation, although each European country has its particularities. While in China, a growing bioethics community has begun engaging not only with scientists and clinicians through capacity-building workshops but also with the public by calling for more deliberation about biological research (Sleeboom-Faulkner \& Hwang 2012). The Ministry of Health's Ethics Committee is planning to publish its findings and opinions to encourage discussion among scientists, clinicians as well as the public. The media in China have also begun playing a role in stimulating deliberation around bioethical issues, though as some journalists pointed out in a BIONET-supported workshop held in Changsha in April 2008, this is often more the case in China's largest cities:

Despite the rising urgency of and media interest in bioethical issues, the media have been poorly equipped to report these issues, especially in cities outside Beijing and Shanghai. Journalists should not be blamed for the insufficiency, as bioethics issues are related to both complicated life science research and difficult ethical issues, such as in the case of how to judge whether certain research could cause harms. (SciDevNet 2008: 4) 
This paper has been accepted for publication in Social Science \& Medicine, and the final (edited, revised and typeset) version of this paper will be published in Social Science \& Medicine, Volume 98, by Elsevier, All rights reserved. (C) Elsevier

What is clear is that each country - whether in Europe or China - is taking active measures to define its ethical and scientific agenda, and indeed to stake their claims to sovereignty. Questions about what forms of scientific practice are to be prohibited - e.g. therapeutic cloning, export of biological samples or provision of experimental stem cell therapies - remain very much anchored in nation states and are often surrounded by commercial as well as national interests as nation states vie for competitive advantage. Biotechnology and advanced biomedical research have been identified as key strategic areas in both the European Union and China (see Gottweis 2009; Ong \& Chen 2011).

While there are no formulas for ensuring the 'best' or 'most inclusive' forms of deliberation, there are plenty of lessons learned and best practices to be consulted and shared. It is one thing to organise global meetings around questions of bioethics, and another to ensure exchange of experiences and ideas between, for example, various national ethics councils or committees about how to organise national deliberation. Should it be through town hall meetings, expert seminars, media campaigns, etc.? Moreover, when scientists enter a cross-cultural collaboration, they are not only bringing with them certain sets of expertise, they are also coming from certain traditions and styles of debating science direction, something that collaborating partners need to be aware of. For example, the question of whether or not research on human embryos should be allowed has not been approached in the same way in China as it has been in Germany, yet in both countries positions have emerged around this exact question. Dialogue and exchange about how various positions have been formed would facilitate the kind of cross-cultural dialogue that is a precondition for research collaboration. 
This paper has been accepted for publication in Social Science \& Medicine, and the final (edited, revised and typeset) version of this paper will be published in Social Science \& Medicine, Volume 98, by Elsevier, All rights reserved. (C) Elsevier

\section{A boom in bioethical legislation}

In both China and Europe, respective organised processes of ethical deliberation feed into national regulatory processes and resulting ethical regulation. Yet, guidelines and regulations are never sufficient in themselves for a number of reasons, beyond the obvious fact that they require execution to be meaningful and practical. First of all, most regulations in advanced biological and biomedical research supplement or specify basic civil and criminal law, and fall under the category of 'soft law', i.e. they are not directly legally enforceable. In Europe, there are often many different instruments used to ensure ethical supervision of research. There are international declarations, national laws and regulations, the regulations of professional associations, recommendations from national ethics councils or commissions, statements of ethical review committees in research institutions or hospitals, ethical requirements of public or private funding bodies as well as ethical requirements of scientific journals (see De Vries et al. 2007).

\section{[TABLE 1 here]}

In China, there has also been somewhat of a 'legislative boom' over the past few decades, corresponding to the policy of opening and transforming China. A key function of legislation at this level is employing standardisation measures as an instrument to foster China's international role as a global player and a modern state, also in life sciences research. Almost every bioethical aspect regarding biomedical manipulations (see Table 1), including those involving human embryonic stem cells, has been covered through 
This paper has been accepted for publication in Social Science \& Medicine, and the final (edited, revised and typeset) version of this paper will be published in Social Science \& Medicine, Volume 98, by Elsevier, All rights reserved. (C) Elsevier

guidelines and regulations in order to protect the rights of human subjects and public morality, however, most regulations do not enforce legal liabilities (civil or criminal) and damages.

As such, we find broad agreement about the fundamental moral concerns and principles laid out in both European and Chinese documents - e.g. the protection of subjects from abuse, informed consent or mandatory ethical review of biomedical research projects. Still, there is a long way from regulation to implementation, a pathway that can be filled with obstacles in the form of a lack of capacity or ambiguous or vague formulations and that can be manipulated against the regulations' intentions. As a result, there are often a diversity of practices with some best practice institutions having developed strong systems for ensuring ethical governance and others still working to build capacity and capability.

Another weak aspect of regulation relates to the process of formulating them. When compared to the fast pace of scientific discovery and research, regulation is usually lagging behind. It can be a laborious and slow process to prepare legislation related to life sciences research involving human subjects not least since it often overlaps the areas of different Ministries/Directorate Generals and also since formulating laws and regulations involved consultations with numerous experts from the legal, bioethical, social and medical fields (see Sariola \& Simpson 2011). 
This paper has been accepted for publication in Social Science \& Medicine, and the final (edited, revised and typeset) version of this paper will be published in Social Science \& Medicine, Volume 98, by Elsevier, All rights reserved. (C) Elsevier

On the other hand, harmonisation processes, partly spurred on by international collaborations can often be used to 'raise the bar'. For instance, if a multi-centre clinical trial involves partners from countries in Europe and China, principal investigators may require that the most stringent ethical requirements are followed, leading partners in other countries to strengthen their ethical governance practices while still complying with national requirements. However, one must not overlook the close ties that private biotech and pharmaceutical companies can have with regulators and indeed the ways in which industry lobbies feed into regulatory processes must be accounted for in terms of raising or lowering ethical ‘bars’ (see Petryna 2009; Abraham and Reed 2003).

Finally, in the context of global science, a number of regulatory gaps appear as different nations adopt different approaches to regulating areas of life science research. That is to say, national regulations cannot in themselves prevent or restrict any kind of research in a global context of regulatory diversity. For example, some countries are considered to have permissive regulation and others restrictive regulation when it comes to stem cell research and/or provision of experimental stem cell therapies. Such regulatory diversity may create uncertainty and has arguably fuelled both 'brain drain/gain' as stem cell scientists travel to work in so-called 'permissive' countries and 'stem cell tourism' as patients travel to various parts of the world to receive experimental treatments not available in their own countries. The point being that global mobility makes it impossible for single nations to prohibit any particular kind of research on their own. Such challenges are intensified when multiple regulatory traditions and regimes are brought into contact through cross-cultural research collaboration. Cross-continental collaboration 
This paper has been accepted for publication in Social Science \& Medicine, and the final (edited, revised and typeset) version of this paper will be published in Social Science \& Medicine, Volume 98, by Elsevier, All rights reserved. (C) Elsevier

inevitably involves multiple legal systems and traditions which in turn calls for clarity about which laws and regulations apply to the practices of researchers, something that should be clarified from the outset of any research collaboration.

\section{Ethical review}

If the spheres of ethical deliberation and ethical regulation contribute to setting a particular legislative and cultural context and/or direction for advanced biomedical research in a country, then the building up of ethical oversight mechanisms has become an important part of the everyday, nitty-gritty of biomedical research. This is because one of the most important instrumental aspects of ethical governance systems is oversight and adherence. For it is the principle objective of all ethical governance systems to protect the rights, safety and wellbeing of human subjects who participate in biological or biomedical research and this implies some kind of oversight of the research process from recruitment of research subjects, carrying out of research, publication of research to follow up of research participants. Institutional Review Boards (IRBs) or Ethics Review Committees (ERCs) are the two most dominant organisational forms of ethical oversight and it is these institutions that scientists will be in direct contact with.

With countries in both Europe and China currently being in the midst of building up such systems of ethical oversight, there are plenty of lessons learned to be shared. It is only in relatively recent years that ethical review systems have come to be organised at a national or trans-national level. In Europe, ethical review boards were established locally on an ad hoc basis from around the 1960s, often as a result of public debates about cases of 
This paper has been accepted for publication in Social Science \& Medicine, and the final (edited, revised and typeset) version of this paper will be published in Social Science \& Medicine, Volume 98, by Elsevier, All rights reserved. (C) Elsevier

misconduct, scandals or disputed practice (see Hall 1991; Hedgecoe 2009). It was not until the 1990s that European governments began taking steps to recognise, consolidate and coordinate their work regionally and nationally. The ways in which the work of ethics review committees is organised varies greatly from country to country, with some emphasising institutional levels and others centralising the task of ethically reviewing scientific research.

In China, there has also been an initial focus on establishing institutional review boards but the government has stipulated that administrative departments of health at the provincial level all set up consultation organizations on ethical review to guide and supervise the ethical review by IRBs under their jurisdiction. According to the Regulations on Ethical Review of Biomedical Research Involving Human Subjects:

\begin{abstract}
Institutions implementing biomedical research involving human subjects and application of relevant technologies, including institutions for medical and health, research, prevention and control of diseases, and healthcare of women and children, shall set up IRBs. IRBs shall mainly undertake the ethical review and carry out the ethical review and supervision over biomedical research involving human subjects and application of relevant technologies by the institutions themselves and those subordinate to them and may accept the entrusted review according to the demands of society; they may also organize and carry out relevant ethical trainings. (MOH 2007: Article 6)
\end{abstract}

Yet, while a requirement to ethically oversee biological and biomedical research involving human subjects has by now been enshrined in national law throughout Europe and China, putting such oversight into practice is a process with numerous hurdles and challenges - which are again complicated when both regions are interactively connected through research collaboration. In China there is great variability of institutional practices 
This paper has been accepted for publication in Social Science \& Medicine, and the final (edited, revised and typeset) version of this paper will be published in Social Science \& Medicine, Volume 98, by Elsevier, All rights reserved. (C) Elsevier

under the same standards - just as in the European region. There are good ethical review practices in 'top' hospitals and laboratories but more problems in less-resourced hospitals and laboratories or in differently developed regions. Among the problems identified by BIONET in China were:

- Lack of independence - many ethical review committees were chaired by the heads of hospitals and external members often did not have voting rights

- Conflicts of interest arising from researchers' financial interests

- Lack of resources to monitor and follow up once research has been approved

- Researchers tend to give yes/no answers with insufficient commentary on issues of researcher qualifications, risk-benefit analyses, informed consent and compensation

- Lack of qualified members for ethical review committees, members may have basic training in Good Clinical Practice but not in ethics

- Lack of resources for ethics committees to train researchers

- There are still large discrepancies in the quality of informed consent forms, examples range from half-a-page to 4-5 pages - insufficient explanation of randomisation, placebo, other available treatments, risks, adverse effects

- No attention to insurance questions - the most frequent source of dispute comes from disagreement about compensation if adverse or harmful effects result from participating in a clinical trial (BIONET 2010a) 
This paper has been accepted for publication in Social Science \& Medicine, and the final (edited, revised and typeset) version of this paper will be published in Social Science \& Medicine, Volume 98, by Elsevier, All rights reserved. (C) Elsevier

In view of these challenges, two constructive proposals have emerged in China: firstly, so-called 'centres of excellence' could play an important role in promoting and sharing their best practices with other less-resourced laboratories and hospitals. Secondly, smaller hospitals and laboratories could pool their resources and, for example, form joint ethical review committees.

Since cross-continental research collaborations will often involve multiple institutions there will be multiple review boards/committees involved as well. And since each institution will have its own particular procedures and traditions of operation, collaborating scientists will need to ensure that their collaborations are compliant with the ethical review requirements of their institutions. This may well require that particular review boards/committees specifically address how cross-continental research collaborations should be reviewed and also calls for cross-continental exchange of best practices and ideas between members of review boards in Europe and China.

\section{Ethical interaction}

A fourth and final sphere or layer of ethical governance consists of the ethical interaction which takes place between researchers and research subjects. Ethical interaction consists of all those occasions when researchers come into contact and work with voluntary research subjects from recruitment to participation and follow up in a particular research project. Traditionally, informed consent procedures and forms have been seen as the most important tool for ensuring that interaction between researchers and patients is ethical and legal. Signed consent forms are used to keep ethical audit trails which, should research 
This paper has been accepted for publication in Social Science \& Medicine, and the final (edited, revised and typeset) version of this paper will be published in Social Science \& Medicine, Volume 98, by Elsevier, All rights reserved. (C) Elsevier

subjects suffer from unintended consequences or disagreements arise, researchers must be able to produce to document that they have acted in accord with best ethical practice standards by communicating due information.

However, in by far most cases (whether in Europe or China), ethical oversight of scientific research ends once a research proposal has been ethically reviewed and approved. There is little follow up or quality control of informed consent processes, not least because of a lack of resources. Yet it is exactly at this stage that research integrity is most under pressure from multiple directions. For instance, universities might be pressuring senior researchers who in turn might be putting pressure on junior researchers to 'get some results', conflicts of interest can arise if researchers have financial interests in the research at hand, community research projects can have unintended consequences on cohesion if certain members of the community are excluded while others are included in research projects, and patients may feel that saying 'no' to participation will affect their access to medical treatment. Moreover, the pressures of limited resources and time mean that informed consent processes can quickly become routinised and bureaucratic, a matter of signing a form with minimal interaction around and explanation of intended research.

While the limitations of informed consent forms and procedural ethics have been discussed at length by many scholars (see Molyneux et al. 2005; Geissler \& Molyneux 2011; Ong 2011), what has been less examined is exactly whose role it should be and how to ensure that ethical interaction takes place in an ethically acceptable and 
This paper has been accepted for publication in Social Science \& Medicine, and the final (edited, revised and typeset) version of this paper will be published in Social Science \& Medicine, Volume 98, by Elsevier, All rights reserved. (C) Elsevier

transparent manner when cross-cultural research collaborations are initiated (a notable exception is Christakis 1992). Since what is particularly at stake in this sphere of ethical interaction are forms of communication and relationship between doctors and patients or scientists and donors, European researchers who work in China and vice versa will be faced with the challenge of understanding the cultural particularities of such interaction when designing their informed consent procedures and in general ethically sensitizing their research projects. What we found through our mapping exercise in the fields of stem cell, clinical and genomic research is that:

1. There is no ready-made answer as to which situations will automatically lead to unethical interaction, but a willingness to acknowledge and analyse potential pitfalls before, during and after research can help ensure that measures are taken to counteract these. A great deal of collaborative social science research and conceptual reflection will be necessary in order to work out the multi-faceted realities to which ethical governance needs to respond on the ground, especially so in cross-cultural collaborations where researchers may be unfamiliar with the legal, cultural, socio-economic and linguistic settings they are working in.

2. When it comes to recruitment of volunteers, particular attention needs to be paid to how questions of who has the capacity to consent and the authority to consent are negotiated in a given socio-economic and/or cultural context. Since this can change from region to region within a country, scientists must ensure that cultural differences are taken into consideration when they design their consent 
This paper has been accepted for publication in Social Science \& Medicine, and the final (edited, revised and typeset) version of this paper will be published in Social Science \& Medicine, Volume 98, by Elsevier, All rights reserved. (C) Elsevier

procedures, and importantly ensure that all those involved with recruiting volunteers and interacting with them respect cultural sensitivities.

3. Ethical interaction between researchers and research subjects in situations where biological samples are procured requires respect as well as social and cultural sensitivity, and donor safety will always be the prime concern (see RehmannSutter 2011). Likewise when biographical, life style or family medical history is obtained from donors through interviews or questionnaires, due social and cultural sensitivity is a requisite.

4. A great deal of thought must be put into study designs and communication with communities and potential research subjects. For example, what might seem like administrative technicalities on paper (e.g. study inclusion criteria) can have unintended stigmatizing consequences in a community (see Patra and SleeboomFaulkner 2010).

\section{Conclusions}

In this article, we have argued that an intensification of cross-continental biomedical and biological research collaborations has generated an urgent need to address questions around the ethical governance of biomedical research collaborations (cf. Geissler et al. 2008; Sleeboom-Faulkner \& Hwang 2012). Whereas the idea behind a 'global bioethics' is that a minimum of common ground can be identified and formulated across countries and cultures, ethical governance of biomedical research collaborations takes its point of departure in actual practices in specific fields around the world. If global bioethics has been critiqued as an imposition of a 'Western' or 'universal' ethical framework that is 
This paper has been accepted for publication in Social Science \& Medicine, and the final (edited, revised and typeset) version of this paper will be published in Social Science \& Medicine, Volume 98, by Elsevier, All rights reserved. (C) Elsevier

external, detached or alien to a given situation, then this is partly because of the fact that individual countries are actively building up national systems of ethical governance. When there is collaboration, (rather than being imposed) such systems presumably meet and are required to co-operate and communicate. One of the first steps in addressing the challenges of collaboration is carrying out the kind of mapping exercise we have as a way to improve understanding of what it is that each partner organisation is 'bringing to' the collaboration.

As a way of organising the complexity of global research collaborations, we have found it helpful to delineate four distinct spheres relevant in the context of ethical governance of biomedical and biological research - namely those of ethical deliberation, ethical regulation, ethical oversight and ethical interaction. When researchers enter into crosscontinental biomedical research collaboration, they are bringing with them their own experiences from these spheres as found in their own national settings. And what we suggest is that, this must be taken into account in the planning, execution, management and oversight of research collaborations. A number of concrete avenues for future attention emerge, which we put forth here as our conclusion:

Accountability and clarity - some forms of biomedical research are allowed in some countries but not in others - e.g. creation of embryonic stem cell lines or therapeutic cloning. As a consequence, what matters most for the governance of research collaboration between Europe and China (or between any other countries or regions) and also within these regions, is that all research should take place accountably within clear 
This paper has been accepted for publication in Social Science \& Medicine, and the final (edited, revised and typeset) version of this paper will be published in Social Science \& Medicine, Volume 98, by Elsevier, All rights reserved. (C) Elsevier

national regulations and ethical frameworks there should not be any ambiguity as to which regulations are applicable.

Ethical capacity building of principal investigators - ethical review committee members have long been targeted for capacity building. Yet ethical, cultural and social capability development is not only something that should be directed at such members, rather ethical capacity building should also be provided for principal investigators of research projects and other relevant research staff, as it is they who will be identifying and analysing their target populations for study recruitment. Moreover, while ethical review of research projects before they commence is of course important, perhaps more important is to set up mechanisms for ethical oversight through the duration of a scientific project (e.g. quality control of informed consent procedures, interviews with research subjects and researchers), and evaluation afterwards.

Inter-disciplinary collaboration in biomedical research - social sciences can contribute through in depth, empirical research among participants in advanced life science research projects to help identify ethical challenges arising from researcher-research subject interaction in particular settings. In particular, they can enhance the soft skills required in ethical governance and communication between cultures. Ethical review requirements could include social scientific inputs into the identification of potential ethical problems arising from biomedical research.

\section{References}


This paper has been accepted for publication in Social Science \& Medicine, and the final (edited, revised and typeset) version of this paper will be published in Social Science \& Medicine, Volume 98, by Elsevier, All rights reserved. (C) Elsevier

Abraham, J. \& Reed, T. (2003). Reshaping the carcinogenic risk assessment of medicines: international harmonisation for drug safety, industry/regulator efficiency or both? Social Science and Medicine. 57(2): 195-204

Alora \& Lumitao (2001). Beyond a Western Bioethics: Voices from the Developing World. Georgetown University Press

Angell, M. (1997). The ethics of clinical research in the Third World. New England Journal of Medicine, 337(12), 847-849.

BCRC (2012) Sino Danish Breast Cancer Research Centre, http://www.bcrc.dk/sinodanish-breast-cancer-research-centre.6, accessed on: 25 January 2012

Bharadwaj, A. \& Glasner, P. (2009) Local Cells, Global Science: The Rise of Embryonic Stem Cell Research in India, London: Routledge

BIONET (2010a) Recommendations on best practice in the ethical governance of SinoEuropean biological and biomedical research collaborations, BIONET Expert Group Report, London: London School of Economics, available at: http://www2.lse.ac.uk/BIOS/research/BIONET/

Bhutta, Z. (2004) Standards of Care in Research Should Reflect Local Conditions and not the Best Western Standards. British Medical Journal 329: 1114-15.

Braun, K. \& Kropp, C. (2010). Beyond Speaking Truth? Institutional Responses to Uncertainty in Scientific Governance. Science, Technology \& Human Values, 35: 771-782.

China Trials (2008) China Trials 2008: Global Clinical Development Summit, http://www.chinatrialsevent.com/: accessed on 22 January 2012

Christakis, NA (1992) Ethics are local: Engaging cross-cultural variation in the ethics for clinical research. Social Science \& Medicine. 35(9): 1079-1091

Crane, J. (2010). Adverse events and placebo effects: African scientists, HIV, and ethics in the 'global health sciences'. Social Studies of Science 40(6): 843-870

DeCosta, A., D’Souza, N., Krishnan, S., Chhabra, M. S., Shihaam, I., \& Goswami, K. (2004). Community based trials and informed consent in rural north India. Journal of Medical Ethics, 30, 318-323.

De Vries, R, Turner L, Orfali K and Bosk C (eds) (2007) The View from Here: Bioethics and the Social Sciences. Oxford: Blackwell

Döring, O. (Ed) (2009). Life Sciences in Translation - A Sino-European Dialogue on Ethical Governance of the Life Sciences, BIONET Textbook, available at: http://www2.lse.ac.uk/BIOS/research/BIONET/

Geissler, P.W. \& Molyneux, C. (Eds.) (2011) Evidence, Ethos and Experiment. The Anthropology and History of Medical Research in Africa. Oxford: Berghahn Books.

Geissler, P.W., Kelly, A., Imoukhuede, B. \& Pool, R. (2008) "He is now like a brother, I can even give him some blood"-relational ethics and material exchanges in a malaria vaccine "trial community" in The Gambia. Social Science and Medicine, 67(5): 696707.

Gottweis, H. (Ed) (2009). Biopolitics in Asia. New Genetics and Society, 28(3)

Hall, D. (1991) The research imperative and bureaucratic control: The case of clinical research. Social Science and Medicine. 32(3): 333-342 
This paper has been accepted for publication in Social Science \& Medicine, and the final (edited, revised and typeset) version of this paper will be published in Social Science \& Medicine, Volume 98, by Elsevier, All rights reserved. (C) Elsevier

Hedgecoe AM (2009) A form of practical machinery: The origins of research ethics committees in the UK, 1967-1972. Medical History 53: 331-350.

Jasanoff, S. (2007). Designs on Nature. Science and Democracy in Europe and the United States. Princeton University Press.

MOH (2007). Regulations on Ethical Review of Biomedical Research Involving Human Subjects. Ministry of Health, People's Republic of China.

Molyneux, C.S. \& Geissler, PW (2008). Ethics and the ethnography of medical research in Africa. Social Science \& Medicine. 67(5): 685-695

Molyneux, C.S., Wassenaar, D.R., Peshu, N. \& Marsh, K. (2005). "Even if they ask you to stand by a tree all day, you will have to do it (laughter)!" - community voices on the notion and practice of informed consent for biomedical research in developing countries. Social Science and Medicine, 61(2): 443-454.

Ong, A. \& Chen, N. (Eds) (2010). Asian Biotech: Ethics and Communities of Fate. Durham: Duke University Press.

PAGANINI (2007) Participatory Governance and Institutional Innovation The New Politics of Life, Summary Report of the PAGANINI Project, Vienna: University of Vienna

Patra, P. K. \& M. Sleeboom-Faulkner (2010) Population Genetic Screening for Sickle Cell Anaemia among the Rural and Tribal Communities in India: The Limitations of Socio-ethical Choice. In M. Sleeboom-Faulkner (ed.) Frameworks of Choice: Predictive \& Genetic Testing in Asia, Amsterdam: University of Amsterdam Press. Chapter 4 (2010).

Petryna, A. (2007). Clinical Trials Offshored: On Private Sector Science and Public Health. BioSocieties, 2, 21-40.

Petryna, A. (2009). When Experiments Travel: Clinical Trials and the Global Search for Human Subjects. Princeton: Princeton University Press.

Rehmann-Sutter, C. (2011). Meanings of Informed Consent: How to Consider Participants' Views on the Ethics of Biobanking. Medicine and Philosophy China, 32(10): 17-19, and 32(11): 22-24 and 32 (in Chinese)

Resnik, D. (1998). The ethics of HIV research in developing nations. Bioethics, 12(4), 286-306.

Rosemann, A. (2011) Modalities of value, exchange, solidarity: the social life of stem cells in China. New Genetics and Society, 30(2), 181-192.

Sariola, S. \& Simpson, B. (2011) Theorising the 'human subject' in biomedical research: International clinical trials and bioethics discourses in contemporary Sri Lanka. Social Science \& Medicine. 73(4): 515-521

SciDevNet (2008) Reporting Bioethics Changsha Workshop - Final report, Institute of Science and Technology Journalism and Communication, Hunan University, Changsha, 31 March - 1 April 2008, available at: http://www2.lse.ac.uk/BIOS/research/BIONET/

Sleeboom-Faulkner, M. (ed.) (2010) Frameworks of choice: Predictive \& genetic testing in Asia (pp. 11-26). Amsterdam: University of Amsterdam.

Sleeboom-Faulkner, M. (2009). Human Genetic Biobanks in Asia: Politics of trust and scientific advancement. London: Routledge. 
This paper has been accepted for publication in Social Science \& Medicine, and the final (edited, revised and typeset) version of this paper will be published in Social Science \& Medicine, Volume 98, by Elsevier, All rights reserved. (C) Elsevier

Sleeboom-Faulkner, M. \& Hwang, S. (2012). Governance of stem cell research: public participation and decision-making in China, Japan, South Korea and Taiwan. Social Studies of Science. DOI: 10.1177/0306312712450939

Sunder Rajan, K. (2006). Biocapital: the Constitution of Postgenomic Life. Durham: Duke University Press.

Tangwa, G.B. (1996) Bioethics: An African Perspective. Bioethics. 10(3): 183-200 
This paper has been accepted for publication in Social Science \& Medicine, and the final (edited, revised and typeset) version of this paper will be published in Social Science \& Medicine, Volume 98, by Elsevier, All rights reserved. (C) Elsevier

\section{Table 1}

China's growing bioethical regulatory framework

The Chinese legal system consists of a range of different regulatory instruments. Laws (fă 法) are passed by the People's Congress or its standing committee and are fully enforceable by the responsible institution specified in the law. Regulations (tiáo lì 条例) are approved by the State Council and are also enforceable. Technical norms or standards (jì shù guī fàn 技术规范) which are intended to ensure safety and effectiveness, and ethical principles (lún lĩ yuán zé 伦理原则) which are intended to maintain social order, on the other hand are only enforceable if they are specifically authorized in the text of a law or regulation. Finally, there are also administrative measures (guăn lǐ bàn fă 管理辦法) which are directed at the administration and management of certain research and therapeutic practices and which are binding for those institutions, which are licensed to carry out these practices.

As concerns life sciences research these have been some of the key regulatory stipulations concerning biological sample collection, manipulation of human biological materials and testing of biological therapies on humans:

1998: Interim Procedures for Human Genetic Resources Administration (State Council, Ministry of Science and Technology and Ministry of Health) led to the establishment of the Chinese Human Genetic Resources Administration Office. These procedures were strengthened in 2003 and they specify rules for exporting and importing genetic materials.

2003: Regulations on Standards and Norms for Clinical Drug Research Quality Control (State Food and Drug Administration) established Good Clinical Practice guidelines including protection of research participants

2003: Ethical Guiding Principles for Research on Human Embryonic Stem Cells (Ministry of Science and Technology and the Ministry of Health) set out guidelines for what kinds of research and manipulation would be acceptable 2004: Administrative Measures on Biosafety in Laboratories with Pathogenic Microorganisms (State Council, Ministry of Science and Technology) 2007: Regulations on Misconduct in Scientific Research (Ministry of Science and Technology), led to the establishment of a science ethics committee and a supervision office to stem academic fraud and plagiarism.

2007: Regulations on Ethical Review of Biomedical Research Involving Human Subjects (Ministry of Health)

2009: Administrative Measures on Clinical Applications of Medical Technologies (Ministry of Health), prohibits clinical use of embryonic stem cells and introduces new approval procedures for autologous stem cell therapies.

2010: Guidelines on Ethical Review of Drug Clinical Trials (Ministry of Health and State Food and Drug Administration) 